Article

\title{
Electric Power Investment Risk Assessment for Belt and Road Initiative Nations
}

\author{
Jiahai Yuan ${ }^{1,2, *}$, Yurong Zeng ${ }^{1}$, Xiaoxuan Guo ${ }^{1}$, Yu Ai $^{1}$ and Minpeng Xiong ${ }^{1}$ \\ 1 School of Economics and Management, North China Electric Power University, Beijing 102206, China; \\ 1172206225@ncepu.edu.cn (Y.Z.); 1172206244@ncepu.edu.cn (X.G.); 1172206192@ncepu.edu.cn (Y.A.); \\ 50600182@ncepu.edu.cn (M.X.) \\ 2 Beijing Key Laboratory of New Energy and Low-Carbon Development, North China Electric Power \\ University, Beijing 102206, China \\ * Correspondence: 50601511@ncepu.edu.cn; Tel.: +86-10-6177-3099
}

Received: 2 August 2018; Accepted: 27 August 2018; Published: 31 August 2018

\begin{abstract}
In recent years, Chinese companies' investment in overseas electric power has grown rapidly. Chinese enterprises with matured technology and abundant talent in the field of electric power and electric power investment are becoming the focus of Chinese enterprise investment. However, just like any other energy investment, electric power investment has various potential risks, including economic risk, financial risk, social risk, political risk, electric power foreground risk, resource risk, and environmental risk. To specifically measure electric power investment risk, this article proposed a nine-dimensional indicator system for countries along China's 'Belt and Road Initiative'. Moreover, a fuzzy integrated evaluation model ground on the entropy weight was established to evaluate the electric power investment risk of 21 countries along China's Belt and Road Initiative. The result of research shows that electric power foreground and Chinese factors have become the major underlying determinants of electric power investment risk, while coal power economy, renewable power economy, and political risk should also be attached enough attention when making investing decisions. In conclusion, the optimal choices for China's electricity investment are determined after balancing electric power foreground and basic factors. After analyzing investment risks of various countries, this paper puts forward policy suggestions, which can help Chinese enterprises avoid electric power investment risks and improve investment efficiency.
\end{abstract}

Keywords: electric investment assessment; Belt and Road Initiative; entropy weight method; fuzzy integrated assessment model

\section{Introduction}

In September and October 2013, Chinese General Secretary Xi Jinping resoundingly put forward the construction of two major initiatives: a "Silk Road Economic Belt" and a "21st Century Maritime Silk Road", which were collectively called the "Belt and Road initiative" (BRI). This initiative has attracted the attention of the international community and more than 100 countries and international organizations participated in the BRI in different forms up until now. Among them, over 80 countries and international organizations have signed cooperation agreements with China.

The "Belt and Road Initiative" focus on interregional cooperation with energy cooperation as its focal spot. Electricity is one of the most important basic energy industries and matters vital to national well-being and the people's livelihood, which has been listed as a development priority in the economic development strategies of various countries in the world. Electricity also creates conditions and guarantees for further economic cooperation with the nations along the routes. In recent years, demand for electric power facilities in BRI countries is growing in contrast to the saturated electric 
power market in China [1]. As one of world top electricity-consuming nations, China's electric power technology has reached the world's advanced level and the clean utilization of coal power has achieved great results. With the implementation of the Belt and Road Initiative, electric power construction, equipment manufacturing and investment companies in China are embracing a rare opportunity [2]. Chinese companies should give full play to their own advantages to seize opportunities and strive to achieve win-win cooperation with the BRI countries to promote the internationalization of electric power production capacity.

Overseas electric power investment is a positive response to the national strategy and an inevitable choice of power enterprises after the domestic electric power market is saturated. According to the "China power industry annual development report" (https:/ / chinaenergyportal.org/en/cec-issues-chinapower-industry-annual-development-report-2016) from China Electricity Council, BRI nations have become hotspots for electricity investment: by 2016, China electric power enterprises have already carried out investment business and contracted projects in 52 BRI countries including 120 large-scale contracted projects which the total contract value is over 27.5 billion U.S. dollars [3]. According to the International Energy Agency forecast, by the end of 2035, two-thirds of energy investment will be concentrated in emerging economies, mainly in Asia, Africa, and other regions [4].

At the same time, the great potential risk of overseas electric power investment has become the main factor affecting the investments profit due to three main characteristics of electric power investments: long investment period, high investment uncertainty, and the non-storability of electricity. Given the fact that many resource-rich countries have singular economic structures, prominent political risks, and backward electric industry, electric power investment in those countries is always accompanied with significant risk. Over the past 10 years, overseas electric power investment history of Chinese-funded enterprises has not been smooth and more than half of the projects have faced various challenges in the investment, construction, and operation phases. Consequently, a comprehensive evaluation of electric power investment risks in BRI nations is a prerequisite for smooth investment proceeds, which might be useful to provide policy suggestions for Chinese company overseas electric power investments decision-making.

Electric power investment risk assessment is one of the research priorities in energy risk management. The investment risks of power plants or power grids have been studied by various scholars. Darrin Grinmsy and Mervyn K. Lewis studied the financing of India's first foreign-invested power project. The study analyzed policy, power trading, and other risk factors, and proposed important risk factors and corresponding avoidance methods for the financing and construction of the project [5]. Liu and Yan analyzed the influencing factors and relationship chains of power investment risk, presented the factors affecting the surface, middle, and deep factors of investment risk in the electric power industry and introduced a fuzzy comprehensive evaluation model [6]. Shakouriet et al. [7] used the analysis networks method (ANP) to analyze the risk of hydropower engineering, established a multi-level ANP structural model of risk factors and elaborated the solution to the model. Finally, a hydropower project was verified as an example. Liu et al. [8] established a grid enterprise operational capability evaluation indicator system including electric power supply capacity, grid transmission, and distribution capacity and demand side management capability. The network hierarchy analysis method was utilized to determine the indicator weight, and then the evaluation was done by linear weighting method. Engelbert, J. et al. [9] studied the impact of transmission capacity on enterprise value and operational risk, showing that firm value consists of the value of the transmission capacity in place plus the value of a short put and a short call option that is the result of the SO's balancing actions. Javier Farfan et al. [10] proposed national sustainable development indicators for the electric power industry to assess the level of development of the power industry in various countries and measure investment risks. Gal, N. and Milstein et al. [11] studied the effect of natural-gas fuel cost uncertainty of capacity investment and price in a competitive electricity market using a two-stage model. Tietjen, O. [12] compared investment risks in renewable and fossil fuel dominated electric 
power markets and studied the market risk of different investment portfolios. It was found that renewable energy economy was most affected by electricity price.

At present, most of the literature in China only study the risks of electric power investment in a single aspect but does not consider the electric power investment industry comprehensively [13]. Liu et al. [14] proposed a hierarchical risk management framework for electric power generation companies' electric power transactions in response to various trading risks in the electricity market. The framework includes objectives and condition confirmation, risk control, and risk assessment. This paper uses modern portfolio theory to maximize profits in the range of defenses that electric power generation companies can afford. In view of the uncertainty of electricity price, Kang Chongqing [15] proposed an uncertain risk decision-making method for electric power generation enterprises in the electricity market environment. The method uses the expected value of the income, standard deviation, the indifference curve, and the corresponding benefit function to describe the different risk attitudes of the decision makers. Zhang et al. [16] used the real option model to study China's renewable energy investment risk, considered a variety of indeterminate factors and conducted sensitivity analysis to determine the best investment strategy. Fei Duan et al. [17] proposed a fuzzy integrated evaluation model using the entropy weight to rate the energy investment risk of 50 BRI countries, which mainly focus on oil and gas. Jiahai Yuan et al. [18] researched the impact on the value of coal power companies under different stress scenarios and constructed a stress testing framework for environmental risks that affect financial costs. Yuan J. et al. [19,20] and Zhao et al. [21,22] analyzed the economics of coal power under a changing market landscape. Several recent papers have addressed the role of coal power in sustainability of China [23-25]. The above indicates that previous studies on the assessment of electric power investment risks have focused on specific projects, mainly involving some micro-level risk factors, which seldom targeted country-specific risk assessments for electric power investment.

The concept of national risk originated from the booming cross-border business of international banks in the 1950s. The accompanying overseas credit risk is called national risk or sovereign risk [26]. In the 1960s, the new Cuban government nationalized the huge amount of US property, which caused a great shock in the academic and business circles. The study of national risks began. Herring et al. argued in his research that national risks include social risks, political risks, and micro risks [27]. Cosset believes that the removal of extreme political events, repayment will, and repayment ability are the main assessment content and sufficient foreign exchange reserves are an important factor [28]. The Economist Intelligence Unit defined country risk as a comprehensive measurement sovereign debt risk, liquidity risk, and risk in the domestic banking sector. It can be compared horizontally between different countries, or vertically across a country [29]. The International Country Risk Guide (ICRG) is a very authoritative national risk assessment guide. Since 1982, the risk ratings of countries around the world have been released every month. The overall evaluation results are affected by three indicators: political risk, economic risk, and financial risk. Moody's, S\&P, Fitch, and other institutions all carry out sovereign credit ratings for countries, but the methods and models they use are kept confidential. Because the national sovereign credit rating involves many evaluation indicators and complex content, the international analysis usually relies on the analysis reports of the major credit rating agencies to measure the national risks of each country.

The above studies show that most scholars mainly study the risks of single projects, while the investment risk research for electricity is in its infancy and the overseas electric power investment risk research from the perspective of Chinese enterprises is still blank. There are two unique features of Chinese enterprise power overseas investment risk: First, unlike general manufacturing investment, electric power investment is greatly affected by factors such as local resource endowment and electricity demand. Second, in the process of Chinese enterprises overseas power investment, the influence of China's diplomatic relations with the invested countries on investment cannot be ignored. As China's power generation technology is mature and the domestic power market is becoming saturated, overseas power investment has become an important strategy for Chinese electricity companies. 
For the above reasons, it is very practical to construct a scientific and reasonable evaluation system to measure the risk of overseas power investment.

\section{Materials and Methods}

This section aims to rationalize the risk of electric power investment for BRI countries. Firstly, 45 indicators were extracted from nine dimensions, including economic foundation, finance and trade, social development, political risk, environmental constraints, Chinese factors, electricity potential, coal power economy, and renewable power economy. An overseas electric power investment risk indicator evaluation system from Chinese perspective was proposed. Then, the entropy weight method is used to identify the indicators weight, and the fuzzy comprehensive evaluation model is adopted to evaluate the power investment risk of the main BRI countries.

\subsection{Indicator System for the Evaluation of Electric Power Investment Risk}

A scientific and comprehensive evaluation indicator system is a prerequisite for a reasonable evaluation. In order to cover all aspects of electric power investment risk, this paper selects nine risk dimensions, combining the common country risk and the specific risk of power investment. Because the entropy method is being used, the number of indicators in each dimension will greatly affect the dimension weight. Therefore, in order to avoid the weight difference caused by the different number of indicators, each dimension uses five indicators, a total of 45 indicators.

As for the selection of dimensions, this paper drew on the global evaluation system, including Standard \&Poor's and Moody's credit rating, and obtained the first five dimensions comprehensively. The selection of indicators under each dimension was also combined with international experience, and the most representative 25 indicators were selected. The last three dimensions are the highlights of this paper, highlighting the characteristics of power cooperation from three perspectives of electricity, coal power, and renewables. Based on the objectiveness of the indicators and the availability of data, this paper selected 20 indicators. Two kinds of indicators are hard to choose: one is price indicator and the other is technology indicator. Although price indicators, such as electricity price and coal price, also have a great impact on the investment risk of electric power, these kinds of indicators are difficult to use directly because the economic level of countries varies greatly and the bearing capacity of price indicators is also different. In addition, there is no available data. For technical indicators such as the technical level of the unit and cogeneration situation, data for indicators like these is also difficult to obtain or quantify, so they cannot be used as rating indicators. Finally, considering the background of global energy transformation and climate governance, environmental constraints have become more and more significant. As one of the main factors causing the risk of electric power investment, environmental constraints also need to be included. The selection of this indicators of this dimension balances the two aspects: environmental performance and environmental goal. Environmental performance is the first four indicators and environmental goal refers to INDC (intended nationally determined contributions). Specific indicators are presented in Table 1. 
Table 1. Overseas electric power investment risk evaluation indicator system.

\begin{tabular}{|c|c|c|c|c|}
\hline Dimensions & Indicators & Indicator Description & Source & Standardization \\
\hline \multirow{5}{*}{ Economic Foundation } & Economic scale & GDP Total & WDI [30] & Logarithmic \\
\hline & Development level & GDP per capita & WDI & Logarithmic \\
\hline & Economic growth & GDP growth rate & WDI & Linear \\
\hline & Inflation index & Annual inflation rate measured by the GDP deflator & WDI & Power function \\
\hline & Debt level & Public debt as a percentage of GDP & IEF [31] & Power function \\
\hline \multirow{5}{*}{ Finance and Trade } & Financial freedom & Degree of convenience of international business capital flows & IEF & Linear \\
\hline & Business Freedom & $\begin{array}{l}\text { Degree of facilitation of international business operations by } \\
\text { transnational corporations }\end{array}$ & IEF & Linear \\
\hline & Exchange rate changes & $\begin{array}{l}\text { Mean variance of the official exchange rate (equivalent to 1USD } \\
\text { in local currency unit, period average) }\end{array}$ & WDI & Power function \\
\hline & Trade opening degree & Imports of goods and services as a share of GDP & WDI & Power function \\
\hline & Investment level & NET inflow of foreign direct investment as a share of GDP & WDI & Power function \\
\hline \multirow{5}{*}{ Social Development } & Population growth & Percentage of annual population growth & WDI & Linear \\
\hline & Urbanization rate & Urban population (\% of total population) & WDI & Linear \\
\hline & Unemployment & Proportion of unemployed population & WDI & Power function \\
\hline & Social crime & Crime index & Numbeo [32] & Linear \\
\hline & Education level & Proportion of secondary school population & WDI & Linear \\
\hline \multirow{5}{*}{ Political Risk } & Control of corruption & Degree of government controls over corruption & WGI [33] & Linear \\
\hline & Political stability and absence of violence & $\begin{array}{l}\text { Quality of public service, administrative department, and its } \\
\text { independence from politics, policy formation, } \\
\text { and implementation }\end{array}$ & WGI & Linear \\
\hline & Government stability & Government stability, political violence, and terrorism & WGI & Linear \\
\hline & Rule and law & $\begin{array}{c}\text { Establishment, perfection, enforcement, and supervision of } \\
\text { laws and regulations }\end{array}$ & WGI & Linear \\
\hline & War and conflict & Number of people killed in war in the last $10 y e a r s$ & WB [34] & Power function \\
\hline
\end{tabular}


Table 1. Cont.

\begin{tabular}{|c|c|c|c|c|}
\hline Dimensions & Indicators & Indicator Description & Source & Standardization \\
\hline \multirow{5}{*}{ Chinese Factors } & Degree of dependence on import and export & $\begin{array}{l}\text { Total exports to China/total exports of a country }+ \text { imports } \\
\text { from China total trade/total import of a country }\end{array}$ & National Bureau of Statistics, WB [35] & Power function \\
\hline & Degree of investment dependence & $\begin{array}{l}\text { Proportion of bilateral investment between China and } \\
\text { one country }\end{array}$ & Ceic, WDI & Linear \\
\hline & Partnership & $\begin{array}{l}\text { A cooperative relationship between states for the search for } \\
\text { common interests }\end{array}$ & BRI Big Data Report [36] & Linear \\
\hline & Bilateral agreements & $\begin{array}{c}\text { Coordination of tax and trade agreements between the two } \\
\text { sovereign states }\end{array}$ & BRI Big Data Report & Linear \\
\hline & Date of establishment of diplomatic relations & National time of diplomatic relations with China & Chinese Foreign Ministry [37] & Linear \\
\hline \multirow{5}{*}{ Environmental Constraints } & Emission level & Per capita carbon emission level/per capita metric ton & IEA [38] & Linear \\
\hline & Emissions growth & Per capita carbon emission growth level & IEA & Linear \\
\hline & Water pressure & 2030BAU situation water pressure & $\begin{array}{l}\text { WRI Water pressure national } \\
\text { rankings data set [39] }\end{array}$ & Linear \\
\hline & PM2.5 & Particulate matter concentration PM2.5 $\left(\mu \mathrm{g} / \mathrm{m}^{3}\right)$ & W.H.O. [40] & Linear \\
\hline & NDC Target & Ratio of current emission value to NDC emission value & INDCs [41] & Linear \\
\hline \multirow{5}{*}{ Electric Power Foreground } & Electrified rate & Proportion of people with electricity services & WB & Power function \\
\hline & Electrification rate & $\begin{array}{c}\text { Proportion of electricity consumption to primary } \\
\text { energy consumption }\end{array}$ & WB & Linear \\
\hline & Power demand growth & Average annual growth of electricity demand & WB & Linear \\
\hline & Power import degree & NET electricity imports as a proportion of total output & IEA & Power function \\
\hline & Per capita power consumption & 2015 annual per capita electricity consumption & WB & Linear \\
\hline \multirow{5}{*}{ Coal Power Economy } & Coal Surplus degree & Coal storage and production ratio & EIA [42] & Power function \\
\hline & Proportion of electric coal & Proportion of coal for coal production & IEA & Linear \\
\hline & Coal Power Planning & $\begin{array}{l}\text { Ratio (absolute value) of planned installed capacity of coal and } \\
\text { electricity to the total capacity of existing generators }\end{array}$ & Prosperity and decline [43] & Power function \\
\hline & Proportion of coal and electricity & $\begin{array}{l}2014 \text { annual coal electricity generation proportion of total } \\
\text { power generation }\end{array}$ & WB & Linear \\
\hline & Coal power growth & 2014 annual average growth rate of coal power generation & WB & Power function \\
\hline \multirow{5}{*}{ Renewable Power Economy } & Renewable generating capacity & Non-water renewable energy 2014 annual generating capacity & WB & Power function \\
\hline & Planning renewable machine & $\begin{array}{l}2030 \text { planning the ratio of renewable installed capacity to the } \\
\text { total amount of the existing generation installed (absolute value) }\end{array}$ & WB & Linear \\
\hline & Growth rate of PV power generation & 2012-2017 annual growth rate of PV generation & BP [44] & Power function \\
\hline & Wind power generation growth & 2012-2017 annual wind power generation growth & BP & Power function \\
\hline & Hydropower generation growth & 2010-2015 annual hydropower generation growth rate & WB & Power function \\
\hline
\end{tabular}


Economic foundations reflect the basic state of the national economy of BRI nations, which affects the security and basic benefits of investment; finance and trade reflect the development of finance and the trade domain in resource nations. Financial and trade conditions affect the finance costs and fund flows, which greatly determines the progress and income of overseas investment. Social development reflects the social progress of BRI country. A high level of social development can help the orderly management, avoid potential social risks, and facilitate the smooth development of overseas investment activities of enterprises. Political risk mainly focuses on the stability of the government of the invested country and the governance level of the local management department. In extreme cases, the local political situation will make a fundamental impact on the income of electric power investment. A stable political environment will be helpful to ensure the electric power investment to go smoothly. The Chinese factor mainly reflects the bilateral relationship between China and the invested country. The harmonious diplomatic relationship and close trade cooperation can ease the conflict and reduce the investment risk. Environmental constraints focus on the assessment of environmental protection and ecological conditions in the invested country. Since the macro-policy orientation and taxation system are greatly affected by environmental constraints, environmental constraints of the investing country should be paid attention for sustainable development of electric power investment. The electric power foreground is one of the most important indicators to measure the investment risk. A great electric power foreground reflects the country's future strong electricity demands, which means that the current installed capacity may not be able to meet that demand. Coal power economy measures the feasibility of coal power investment. Coal power is stable, reliable with low cost, and can also be used in peak operation or heating. China's coal power technology is relatively advanced and mature, so coal power investment is the key investment highlights of power investment of Chinese enterprises. In countries with abundant coal resources and more coal power plants have higher investment value in coal power. Renewable power economy reflects the feasibility of renewable power generation investment. With the increasing environmental pressure, countries are paying more attention to renewable energy, which leads to a continuous increase of renewable energy planning.

\subsection{Fuzzy Integrated Evaluation Model for National Investment Risk Based on Entropy Weight}

Having established a comprehensive evaluation indicator system, how to determine the weight of each indicator and electric power investment risk level of each country is the focus of this section. At present, the methods for determining the weight of evaluation indicators are mainly divided into subjective valuation method and objective valuation method. The subjective value method (Delphi, AHP, etc.) is based on the knowledge and experience of experts in related fields to empower the indicators. This method takes full account of the actual situation of the project, and the result of empowerment is relatively targeted, but it is easy to be influenced by the subjective preferences of experts. Considering this comprehensively, this paper uses the entropy method to calculate the weight of each indicator, which is more objective. Entropy was originally a thermodynamic concept. It was first introduced by C.E. Shannon and called 'information entropy'. It has been widely used in engineering, social, and economic fields. Compared with other objective assignment methods, the entropy method is more accurate when the number of samples is larger. The number of calculation data in this study is large, which is very suitable to use entropy method. In addition, there are a large number of uncertainties in electric power investment risk, including randomness and ambiguity. Thus, this paper utilizes fuzzy comprehensive evaluation model based on entropy weight method to evaluate the risk. This method is relatively innovative and could avoid subjective assumptions.

The basic idea of the entropy method is to determine the objective weight based on the magnitude of the variability of the indicator. Given that the entropy weight method is relatively mature, the specific calculation can be completed by SPSS or Excel. The calculation steps are not detailed here. Please refer to the appendix for details.

The use of fuzzy evaluation can better convert qualitative evaluation into quantitative evaluation, and conduct an overall evaluation of country risk, with clear and systematic result. This paper 
divides the country risk into five levels and calculates the membership function for each risk level. According to the fuzzy evaluation theory, the final country investment risk evaluation level is the risk level corresponding to the maximum value. As above, the calculation steps are not detailed here. Please refer to the appendix for details.

\subsection{Research Countries for Electric Power Investment Risk Assessment}

There are four principles for the choice of countries: first, China's investment flows or stocks to BRI countries. This paper selects the top 10 countries with the highest investment flows or investment stocks in past three years as the research object. In terms of investment flows, Singapore, Israel, Malaysia, Indonesia, Vietnam, Thailand, Turkey, and Cambodia were selected. In terms of investment stock, Russia, Kazakhstan, Pakistan, Myanmar, and India were chosen [45]. Second, the regional typical countries which refer to the major economies in each region. Consequently, this article chose Poland and the Czech Republic in Europe, South Korea in East Asia, South Africa in Africa, and New Zealand in Oceania. Third, data availability. Some countries have been abandoned due to lack of reliable data, such as Laos and Brunei. Fourth, electric power demand. Excluding some developed countries where the electricity market is saturated, countries with greater power demand-such as Ukraine, Philippines, and Bangladesh—have been added. In addition, although the broader the scope of the study, the more objective the article, this paper will control the research in about 20 countries considering the workload and availability of data. Based on the above reasons, the following countries were selected as research objects. The 21 countries are presented in Table 2.

Table 2. Twenty-one countries for electric power investment risk assessment.

\begin{tabular}{cc}
\hline Country & Region \\
\hline South Africa & Africa \\
Kazakhstan & Central Asia \\
Poland & Central Europe \\
Czech & Central Europe \\
Korea & East Asia \\
Russia & Eastern Europe \\
Ukraine & Eastern Europe \\
New Zealand & Oceania \\
India & South Asia \\
Pakistan & South Asia \\
Bangladesh & South Asia \\
Cambodia & Southeast Asia \\
Burma & Southeast Asia \\
Philippines & Southeast Asia \\
Vietnam & Southeast Asia \\
Malaysia & Southeast Asia \\
Thailand & Southeast Asia \\
Indonesia & Southeast Asia \\
Singapore & Southeast Asia \\
Turkey & West Asia \\
Israel & West Asia \\
\hline
\end{tabular}

\section{Results and Analysis of the Risk}

These 21 countries involve a total population of 2.799 billion, which is $37.17 \%$ of the total world population but only has a GDP of US $\$ 11.56$ trillion, which is only $14.44 \%$ of the world's GDP. As an essential infrastructure area for the development of the national economy, the electric power industry in BRI countries has great potential. According to the World Bank report, the global population of electricity in 2014 was about 1.06 billion, mainly in Africa (57\%), South Asia (32\%), Southeast Asia and the Pacific (7\%), and Latin America (3\%) [34]. The growth rate of electricity consumption in South Asia and Southeast Asia reached $6 \%$, which is far higher than the average growth rate of $2.1 \%$ all over the 
world. From 2016 to 2020, the installed capacity of BRI countries will be about 420 million kilowatts, which will drive investment to exceed 1.2 trillion dollars [46]. Most BRI countries are developing countries and less developed countries. Compared with developed countries, these countries are in low per capita electricity consumption and low electrification levels, which economic development has a strong demand for electricity. The backward technical equipment and limited supply capacity of the BRI countries have brought a broad market for Chinese power generation investment enterprises.

In order to objectively analyze the characteristics of overseas electric power investment, this paper also calculates the four dimensions (economic foundation, finance and trade, social development, and political risk) evaluation results which are applicable to general overseas investment. Through the comparison of the evaluation results, this section analyzes the characteristics of the electric power investment risks of BRI countries in perspective of Chinese enterprises and conducts a comprehensive survey of the investment risks of representative countries.

\subsection{National Investment Risk Assessment Results Based on a Four-Dimension Evaluation System}

General country risk assessment is largely built on four dimensions: economic foundation, finance and trade, social development, and political risk. Based on the basic data and classification standards, this paper uses the method of the previous section to determine the weight of each dimension and each indicator. The specific evaluation results are presented in Table 3. The weights of the economic foundation, finance and trade, social development, and political risk are0.25, 0.22, 0.21 , and 0.32 , which shows that for general overseas investment, political risk has the greatest impact when investing. Apparently, the higher the political risk of a country, the greater the uncertainty that companies face when investing. In other words, investing in a country with high political risk requires sufficient investment profit as a guarantee. Otherwise, it should try to avoid investment in the country. In the dimension of political risk, the weight of corruption control is the largest at 0.12 ; in the economic foundation dimension, the per capita GDP weight is the largest, 0.085 ; in the finance and trade dimension, the investment level weight is the largest, 0.089 .

Table 3. Indicator weights of the four-dimensional indicator system.

\begin{tabular}{|c|c|c|c|}
\hline Dimensions & Weight of Dimensions & Indicators & Weight of Indicators \\
\hline \multirow{5}{*}{ Economic Foundation } & \multirow{5}{*}{0.2537} & Economic scale & 0.0273 \\
\hline & & Development level & 0.0848 \\
\hline & & Economic growth & 0.0523 \\
\hline & & Inflation index & 0.0508 \\
\hline & & Debt level & 0.0385 \\
\hline \multirow{5}{*}{ Finance and Trade } & \multirow{5}{*}{0.2216} & Financial freedom & 0.0888 \\
\hline & & Business Freedom & 0.0253 \\
\hline & & Change of exchange rate & 0.0324 \\
\hline & & Trade opening degree & 0.0494 \\
\hline & & Investment level & 0.0257 \\
\hline \multirow{5}{*}{ Social Development } & \multirow{5}{*}{0.2070} & Population growth & 0.0230 \\
\hline & & Urbanization rate & 0.0389 \\
\hline & & Unemployment & 0.0464 \\
\hline & & Social crime & 0.0449 \\
\hline & & Education level & 0.0538 \\
\hline \multirow{5}{*}{ Political Risk } & \multirow{5}{*}{0.3176} & Corruption control & 0.1220 \\
\hline & & Government effectiveness & 0.0529 \\
\hline & & Government stability & 0.0399 \\
\hline & & Legal and law & 0.0732 \\
\hline & & War and conflict & 0.0298 \\
\hline
\end{tabular}

After using the entropy weight method to calculate the weight of each indicator of four dimensions, the fuzzy comprehensive evaluation model is still adopted to calculate the investment risk level 
of countries in this section. The results of the country risk assessment under the four-dimensional indicator system are shown in Figure 1. Poland, South Korea, Czech, Malaysia, Singapore, New Zealand, and Israel have the lower national risk grades. The highest are for Pakistan, Cambodia, Myanmar, and Bangladesh. Generally speaking, for general overseas investment, advanced economies with better economic bases have more investment advantages and investment risks are fairly limited, while the less developed countries have higher risks. Most of the BRI countries are developing countries with weak economic foundations and large political risks, accompanied with a higher level of national risks for general investment (see the Table A2 for the calculation of the specific membership degree).

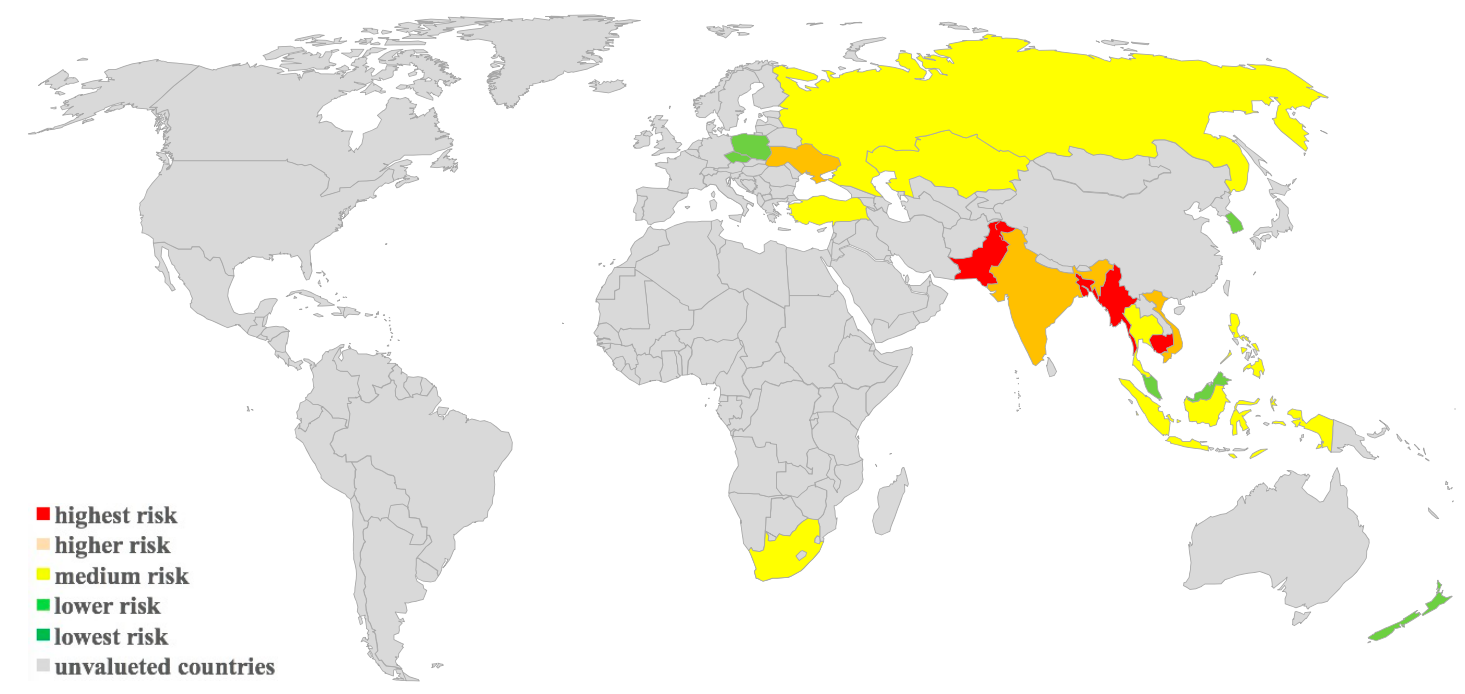

Figure 1. Investment risk map of the four-dimensional indicator system.

\subsection{National Electric Power Investment Risk Results Based on a Nine-Dimension Evalustion System}

This section uses the nine-dimensional evaluation system to measure the risk of electric power investment of 21 BRI countries. The weights of the nine dimensions-economic foundation, finance and trade, social development, political risk, Chinese factor, environmental constraints, electric power foreground, environmental constraints, coal power economy, and renewable power economy-are respectively $0.0843,0.0736,0.0688,0.1056,0.1371,0.0728,0.2162,0.1128$, and 0.1289 . The result of risk assessment shows that the weights of Chinese factor, electric power foreground, environmental constraints, coal power economy, and renewable power economy are greater than political risk, which means that there are some limitations on using traditional dimensions to measure the risk of electric power investment. The two dimensions of electric power foreground and resource economy have a significant impact on the ROI of electric power investment. Additionally, the weight of the Chinese factor ranks second in all nine dimensions, which fully illustrates the impact of the close international relations between the two countries on investment risks should not be ignored. A harmonious relationship can avoid potential risks and ensure smooth investment. In addition, the weight of environmental constraints is not small, which shows that ecological capacity of invested country greatly affects the electric power investment risk. This is closely related to the fact that every country is responding to the pressure of climate change and transforming to a greener, lower-carbon society.

In the estimated results displayed in Table 4, the weight of the indicators of economic foundation, finance and trade, social development, political risk has declined in varying degrees. In the dimension of the electric power foreground, the weight of electrified rate is the highest over 0.137 , illustrating that it is a key factor affecting electric power investment. This can also explain that, despite the greater political risks, countries such as Cambodia and Myanmar can still attract foreign investment to invest in the power industry. In the dimension of Chinese factors, the other four indicators account for more 
than 0.02 except for bilateral agreements which indicates that countries with closer partnership with China have lower risk of power investment. Countries such as Pakistan and Russia score high on this indicator, which also corresponds in with the reality that Chinese companies prefer to invest in Pakistan and Russia.

Table 4. Indicator weights of the nine-dimensional indicator system.

\begin{tabular}{|c|c|c|c|}
\hline Dimensions & Weight of Dimensions & Indicators & Weight of Indicators \\
\hline \multirow{4}{*}{ Economic Foundation } & \multirow{4}{*}{0.0843} & Economic scale & 0.0091 \\
\hline & & Development level & 0.0282 \\
\hline & & Inflation index & 0.0169 \\
\hline & & Debt level & 0.0128 \\
\hline \multirow{3}{*}{ Finance and Trade } & \multirow{3}{*}{0.0736} & Financial freedom & 0.0295 \\
\hline & & Trade opening degree & 0.0164 \\
\hline & & Investment level & 0.0085 \\
\hline \multirow[b]{3}{*}{ Social Development } & \multirow[b]{3}{*}{0.0688} & Population growth & 0.0076 \\
\hline & & Urbanization rate & 0.0129 \\
\hline & & Unemployment & 0.0154 \\
\hline \multirow[t]{3}{*}{ Political Risk } & \multirow[t]{3}{*}{0.1056} & Government stability & 0.0132 \\
\hline & & Legal and law & 0.0243 \\
\hline & & War and conflict & 0.0099 \\
\hline \multirow{5}{*}{ Chinese Factors } & \multirow{5}{*}{0.1371} & Degree of dependence on import and export & 0.0327 \\
\hline & & Degree of investment dependence & 0.0388 \\
\hline & & Partnership & 0.0237 \\
\hline & & Bilateral agreements & 0.0135 \\
\hline & & Date of establishment of diplomatic relations & 0.0284 \\
\hline \multirow{2}{*}{ Environmental Constraints } & \multirow{2}{*}{0.0728} & Emission level & 0.0160 \\
\hline & & Emissions growth & 0.0120 \\
\hline Electric Potential & 0.2162 & Per capita power consumption & 0.0142 \\
\hline \multirow{5}{*}{ Coal Power Economy } & \multirow{5}{*}{0.1128} & Coal Surplus degree & 0.0233 \\
\hline & & Proportion of electric coal & 0.0132 \\
\hline & & Coal power planning & 0.0277 \\
\hline & & Proportion of coal and electricity & 0.0148 \\
\hline & & Coal power growth & 0.0338 \\
\hline \multirow{5}{*}{ Renewable Power Economy } & \multirow{5}{*}{0.1289} & Renewable generating capacity & 0.0240 \\
\hline & & Planning renewable machine & 0.0151 \\
\hline & & Growth rate of PV power generation & 0.0212 \\
\hline & & Wind power generation growth & 0.0361 \\
\hline & & Hydropower generation growth & 0.0325 \\
\hline
\end{tabular}

Figure 2 shows the results of the evaluation under the nine-dimensional indicator system and Table 5 highlights the difference between this result and the results of the four-dimensional evaluation system. In the new evaluation system, 12 of the 21 countries have changed their risk levels: 4 countries with lower risks, 2 countries with medium risk, 2 countries with higher risks, and 4 with the highest risk. $33 \%$ of BRI countries are at a higher risk level, which indicates that electric power investment decisions are still challenging and difficult. In general, it is noticeable that the investment risk of countries with broad electric power prospects has dropped significantly, mainly including countries such as Cambodia and Myanmar. This is mainly due to the low electrified rate, inadequate power infrastructure, and fast growth in electricity demand of these countries. In terms of electric power 
potential, these countries have broader prospects. Therefore, electricity investing in these countries is in line with the actual needs of these countries (see the Table A3 for the calculation of the specific membership degree).

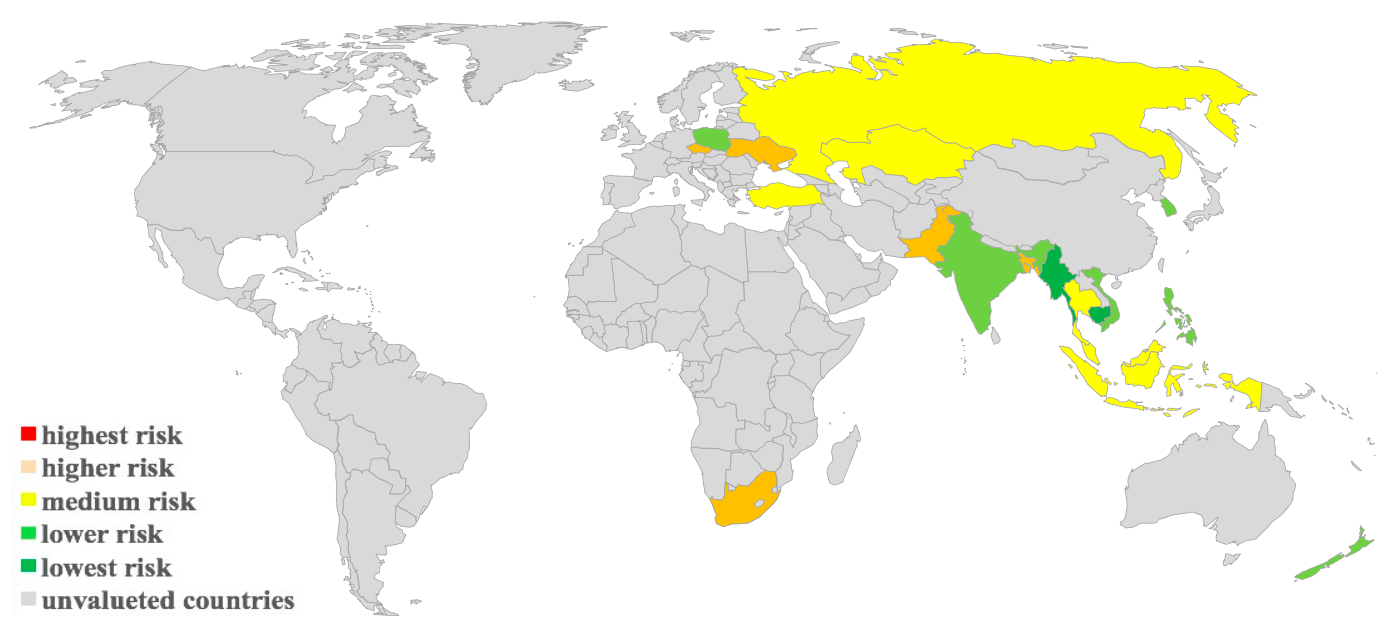

Figure 2. Results of the national risk evaluation for nine dimensions.

Table 5. Results of the integrated evaluation of electric power investment risk.

\begin{tabular}{ccc}
\hline Country & Risk Level & Compared with Four-Dimension \\
\hline Cambodia & lowest risk & $\uparrow 4$ \\
Burma & lowest risk & $\uparrow 4$ \\
Poland & lower risk & $\rightarrow 0$ \\
Korea & lower risk & $\rightarrow 0$ \\
Philippines & lower risk & $\uparrow 1$ \\
New Zealand & lower risk & $\rightarrow 0$ \\
India & lower risk & $\uparrow 2$ \\
Vietnam & lower risk & $\uparrow 2$ \\
Russia & medium risk & $\rightarrow 0$ \\
Kazakhstan & medium risk & $\rightarrow 0$ \\
Malaysia & medium risk & $\downarrow-1$ \\
Thailand & medium risk & $\rightarrow 0$ \\
Turkey & medium risk & $\rightarrow 0$ \\
Indonesia & medium risk & $\rightarrow 0$ \\
Pakistan & higher risk & $\uparrow 1$ \\
Czech & higher risk & $\downarrow-2$ \\
Bangladesh & higher risk & $\uparrow 1$ \\
South Africa & higher risk & $\downarrow-1$ \\
Ukraine & higher risk & $\rightarrow 0$ \\
Singapore & higher risk & $\downarrow-2$ \\
Israel & highest risk & $\downarrow-3$ \\
\hline
\end{tabular}

The comparison results in Table 4 show that the power investment risks of the more developed countries increase, represented by Singapore, Israel, South Africa, and the Czech Republic. Among them, the score of Israel for electric power investment is the lowest in 21 BRI countries. Investment risks in countries such as Pakistan, the Philippines, Bangladesh, India, and Vietnam declined. Investment risks in Southeast Asian countries such as Cambodia and Vietnam have fallen sharply, from the highest risk to the lowest risk; among South Asian countries, investment risks in India and Pakistan also declined. This indicates that the resource potential and the Chinese factor have a huge impact on the evaluation results. The investment risk of the country with greater resource potential or friendly relationship with China is significantly reduced. 
Judging from the evaluation results, Cambodia and Myanmar have the highest scores and have huge investment value. Cambodia is under a low level of electrification and a serious shortage of electricity. The government has been actively attracting foreign investment to utilize its own fuel resources. Myanmar is rich in water resources and the government has implemented an active policy for overseas capital. However, it is important to note that both Cambodia and Myanmar have high political risks and that political turmoil may pose huge risks to Chinese companies. The struggle of the domestic party in Cambodia is fierce and Myanmar's political risks are even worse: the situation in ethnic minority areas is turbulent and domestic nationalism is highly resistant to external investment.

After comprehensive analysis of the scores of BRI countries, it can be found that the scores of Kazakhstan and Vietnam are relatively balanced without obvious shortcomings, which can be ideal electric power investment choices for Chinese enterprises. Kazakhstan is rich in oil, gas, coal, and other resources, with steady economic development and a sound industrial base. It is the country with the most abundant wind resources in the world, having great investment value in both coal power and renewable energy. The domestic electric investment policies are fairly open to electric power investment, especially renewable energy. Currently, Kazakhstan is in a stable political situation and has close relations with China. Thus, despite the weak economic foundation, the overall investment risk is relatively limited. Vietnam is a country with rapid growth in electricity demand in Southeast Asia. The coal potential is quite large, and the government is positive to foreign investment in electricity. Moreover, compared with other Southeast Asian countries, Vietnam's infrastructure construction and labor culture have been increasing steadily, which will help to reduce the cost of electricity investment. However, despite the political stability of Vietnam, due to the South China Sea dispute and the change of the leadership, the policy risks in electric power investment still need to be taken seriously.

From the result of coal power economy, many developing countries along BRI rely on traditional fossil energy sources, mainly coal electric power. In terms of geographical distribution, South Asia and Southeast Asia have broad prospects of coal-fired electric power, especially India, Indonesia, and Pakistan, which are indeed suitable for China's overseas investment in coal power. However, when investing in coal power, enterprises should realize the coordinated development of electricity demand and environmental governance and pay attention to the following aspects when investing in coal power. First, the new coal power should adopt clean and efficient coal power technology, including circulating fluidized bed combustion, supercritical unit and ultra-supercritical unit, which will improve the efficiency of coal power, reduce the intensity of carbon emissions, and avoid backward domestic energy efficiency and technology transfer. Second, new coal power projects should comply with clean production, strictly control pollutant and carbon emissions, and adopt domestic mature desulfurization and denitrification devices.

For countries with abundant renewable resources, compared with coal power, renewable energy has broader development space, including countries rich in wind energy and solar energy represented by Kazakhstan and Russia, water-rich countries represented by India and Myanmar, and archipelagic countries represented by Indonesia and the Philippines. Among them, Russia, Kazakhstan, the Philippines do rank first in the renewable energy economy dimension, indicating that these countries are developing rapidly and have great potential for renewable energy. Renewable energy systems with 'distributed energy plus stored energy' can generate clean electricity while meeting local electricity needs. At present, China's renewable power technology is quite mature and the equipment cost is decreasing. In the next 20 years, the demand for renewable energy from BRI countries will bring opportunities for Chinese enterprises to invest in renewable electricity [47].

For Chinese electricity companies, electric power investment in BRI countries can present both opportunities and challenges. On the one hand, BRI countries have considerable potential for electricity demand. On the other hand, the influence of political and diplomatic factors cannot be ignored. With the deepening of cooperation between China and the BRI countries, the investment environment is expected to further improve, and Chinese enterprises will usher in more investment opportunities. For BRI countries, the Belt and Road Initiative can help open the domestic market and attract more 
foreign investment. As an infrastructure investment, cooperation in the electricity sector can improve the electrification rate, ensure the electricity consumption of residents, and promote the smooth and orderly operation of the electric power market in BRI countries. Furthermore, electric power investment can strengthen the exchange of labor and services and promote new energy technologies and facilitate beneficial and coordinated development between China and the BRI countries.

\section{Conclusions and Implications}

Energy is one of the issues of common concern around the world. The seventh goal of the United Nations Sustainable Development Goals (SDGs) is to ensure affordable and clean energy access [48], however one-fifth of people around the world still do not have access to electricity, and 3 billion people rely on wood, coal, charcoal, or animal waste for cooking and heating. Under such a premise, electric power investment can help countries improve electrification and ensure the supply of electricity, which has far-reaching significance. However, electric power investment has the characteristics of long investment cycle, high investment cost, and strong externality, which affects local sustainable development. In this context, it is of practical significance to integrate the national risks assessment of power investment with environment and sustainability concerns. In this paper, the fuzzy comprehensive evaluation model based on entropy weight is used to comprehensively evaluate the electric power investment risks in 21 countries along China's Belt and Road Initiative, considering not only the economic and political risks, but also electric power market, environmental constraints, and other risks affecting sustainable development.

\subsection{Research Conclusions}

In summary, in the electric power investment risk system, the electric power potential weight is the largest, and the Chinese factor is second to it. These two indicators have the greatest impact on the evaluation results. This shows that Chinese companies should focus on the development prospects of the country's electricity industry and diplomatic situation between China and the country when choosing an investment country. Consequently, for some countries with a basis of long-term cooperation, political risk will not be regarded as the most important factor affecting electric power investment. Besides these two factors, the weights of renewable and coal power planning are also large. In the case of electric power investment, it is necessary to specifically consider the national plans for coal power and renewable energy to make reasonable plans for investment. Finally, indicators such as political risk, economic base, and environmental constraints are also important factors to consider when investing. Compared with the results of national risk assessment, electric power investment does have its own particularity. After considering the unique factors affecting electric power investment such as electric foreground, some countries with lower economic risks become medium or higher risk countries due to lack of an electric power foreground. Consequently, if a simple decision is made only based on economic risk, the investment risk of enterprises will be very high.

The research results indicate that the electric power investment risk in most of the BRI countries is in the middle and lower levels, indicating that the overall electric power investment risk is not trivial. Overall, there are still some countries suitable for Chinese companies to invest in electricity, such as Cambodia, Myanmar, and Vietnam in Southeast Asia; India in South Asia; Kazakhstan in Central Asia; and other countries. Most of the BRI countries are still in the development stage, and Central Asia, Southeast Asia, and South Asia will face a large funding gap in infrastructure, especially in the electric power sector, in the coming decade. The overseas electric power investment of Chinese enterprises not only conforms to the national going-out strategy of China, but also conforms to the practical need of the BRI countries. At present, BRI is developing rapidly. Electric power investment cooperation is still in its infancy and all parties need to cooperate closely to ensure that people benefit from BRI cooperation. 


\subsection{Policy Proposal}

To identify and properly manage the risks that Chinese companies may face in overseas electric power investment, this paper proposes the following policy recommendations:

Focus on specific risks while taking all risks into account. On the one hand, when Chinese companies invest in overseas electric power, they must have an overall grasp of the risks and be particularly wary of certain risks. On the other hand, while avoiding risks, Chinese companies should also have a strategic sense to seize future market opportunities to achieve sustainable investment.

Strengthen the awareness of corporate responsibility, pay attention to environmental protection, and enhance the image of Chinese enterprises. In recent years, international capital markets have shown increasing interest in the concept of ESG (environment, society, and government). When investing in overseas electric power, Chinese companies should take the initiative to upgrade environmental standards, adopt clean and efficient electric power generation technology, strictly control pollutants and carbon emissions, and avoid domestic backward energy efficiency and technology transfer. Chinese enterprises should pay attention to the impact of electricity as an infrastructure on all aspects of the investment country, take the initiative to undertake social responsibilities, and achieve the coordinated development of enterprise development and local environment, society, and government [49].

Establish a national risk early-warning mechanism, regularly publish national investment risk reports and focus on differentiated risk assessments for industries. Due to the asymmetry of information, most Chinese enterprises lack rational estimation of the overseas investment market and do not understand the laws and regulations of the investment country. China should improve its overseas investment information database and regularly issue risk assessment reports of different industries to form a risk warning mechanism to help reduce overseas investment risks [50].

Author Contributions: J.Y. designed the research framework; Y.Z. conducted the analysis and drafted the paper; X.G. and Y.A. collected the data for analysis and polished the manuscript; M.X. provided valuable opinions during the revision.

Funding: The paper is supported by the National Natural Science Foundation of China (71673085), the Fundamental Research Funds for the Central Universities (2018ZD14), Beijing Social Science Fund (16YJB027, and the 111 Project (B18021). We also appreciate the funding by Global Environmental Institute and Energy Foundation China to support the work reported in this paper.

Conflicts of Interest: The authors declare no conflict of interest.

\section{Appendix A}

The calculation process of entropy method and fuzzy evaluation:

Establish indicator system $X$ including $p$ dimensions, that is $X=\left[X_{1}, X_{2}, X_{3}, \cdots, X_{p}\right]$. The kth dimension $X^{k}$ is composed of $n$ indicators, that is $X^{\mathrm{k}}=\left(\begin{array}{ccc}X_{11}^{\mathrm{k}} & \cdots & X_{1 \mathrm{n}}^{\mathrm{k}} \\ \vdots & \ddots & \vdots \\ X_{\mathrm{m} 1}^{\mathrm{k}} & \cdots & X_{\mathrm{m} n}^{\mathrm{k}}\end{array}\right)$, where $X_{\mathrm{m} \mathrm{n}}^{\mathrm{k}}$ represents the value of the $n_{k}^{\text {th }}$ indicator of the $k^{\text {th }}$ dimension of the $m^{\text {th }}$ country. In this paper, $p=9, n=5, m=21$, $\mathrm{X}_{1}, \mathrm{X}_{2}, \mathrm{X}_{3}, \cdots, \mathrm{X}_{9}$ correspond to nine dimensions respectively.

For the matrix of the kth dimension $X^{k}=\left(\begin{array}{ccc}X_{1}^{k} & \cdots & X_{1 n}^{k} \\ \vdots & \ddots & \vdots \\ X_{m}^{k} & \cdots & X_{m n}^{k}\end{array}\right)$, let $M_{j}^{k}=\max \left(x_{i j}^{k}\right), m_{j}^{k}=$ $\min \left(x_{i j}^{k}\right), i=1,2, \ldots, m$, and $j=1,2, \ldots \ldots, n_{k} \cdot M_{j}^{k}$ is the maximum of the $j^{\text {th }}$ indicator of the $k^{\text {th }}$ dimension and $m_{j}^{k}$ is the minimum of the $j^{\text {th }}$ indicator of the $k^{\text {th }}$ dimension.Since the types of raw data are different, different methods are needed to normalize the data. The linear transformation, logarithmic function transformation, and power function transformation are used for normalization. 
Linear transformation is applicable to raw data without extreme values or indirectly obtained data. The higher the score, the lower the risk. Equation (A1) is

$$
y_{i j}^{k}=\frac{x_{i j}^{k}-m_{j}^{k}}{M_{i j}^{k}-m_{j}^{k}} \times 100
$$

Take $y_{i j}^{k}$ as the standardized score (positive correlation is $y_{i j}^{k}$, negative correlation is $\left(100-y_{i j}^{k}\right)$ ).

Logarithmic transformations are mainly used for raw data with extreme values of different orders of magnitude (extreme values are more than three times the quartile gap). For the standardization of different orders of magnitude caused by different scales, the natural logarithm method should be adopted. Equation (A2) is

$$
y_{\mathrm{ij}}^{\mathrm{k}}=\frac{\ln \left(\mathrm{x}_{\mathrm{ij}}^{\mathrm{k}}\right)-\ln \left(\mathrm{m}_{\mathrm{j}}^{\mathrm{k}}\right)}{\ln \left(\mathrm{M}_{\mathrm{ij}}^{\mathrm{k}}\right)-\ln \left(\mathrm{m}_{\mathrm{j}}^{\mathrm{k}}\right)} \times 100
$$

Take $y_{\mathrm{ij}}^{\mathrm{k}}$ as the standardized score (positive correlation is $\mathrm{y}_{\mathrm{ij}}^{\mathrm{k}}$, negative correlation is $\left(100-\mathrm{y}_{\mathrm{ij}}^{\mathrm{k}}\right)$ )

Power functions are mainly applied to raw data with extremes or singular value. The data is still indistinguishable after direct standardization, so the natural power exponent function is adopted to standardize. Since some raw data are negative, the power function with a power exponent of $1 / 3$ is selected

$$
y_{i j}^{k}=\frac{x_{i j}^{k \frac{1}{3}}-m_{j}^{k \frac{1}{3}}}{M_{i j}^{k \frac{1}{3}}-m_{j}^{k \frac{1}{3}}} \times 100
$$

Take $\mathrm{y}_{\mathrm{ij}}^{\mathrm{k}}$ as the standardized score (positive correlation is $\mathrm{y}_{\mathrm{ij}}^{\mathrm{k}}$, negative correlation is $\left(100-\mathrm{y}_{\mathrm{ij}}^{\mathrm{k}}\right)$ ). The normalized matrix $\mathrm{y}^{\mathrm{k}}=\left(\begin{array}{ccc}\mathrm{y}_{1}^{\mathrm{k}} & \cdots & \mathrm{y}_{1 \mathrm{n}}^{\mathrm{k}} \\ \vdots & \ddots & \vdots \\ \mathrm{y}_{\mathrm{m} 1}^{\mathrm{k}} & \cdots & \mathrm{y}_{\mathrm{m} \mathrm{n}}^{\mathrm{k}}\end{array}\right)$ is then obtained, where $\mathrm{k}=1,2, \cdots, \mathrm{p}$. $\mathrm{y}_{\mathrm{m} \mathrm{n}}^{\mathrm{k}}$ means the normalized score of the $\mathrm{n}_{\mathrm{k}}^{\text {th }}$ indicator of the $\mathrm{k}^{\text {th }}$ dimension of the $\mathrm{m}^{\text {th }}$ country (see the Table A1 for specific calculation results).

Calculate the proportion $\mathrm{z}_{\mathrm{ij}}^{\mathrm{k}}$ of the $\mathrm{j}^{\text {th }}$ indicator of the $\mathrm{k}^{\text {th }}$ dimension $X_{\mathrm{j}}^{\mathrm{k}}$ in the $\mathrm{i}^{\text {th }}$ country.

$$
\mathrm{z}_{\mathrm{ij}}^{\mathrm{k}}=\frac{\mathrm{y}_{\mathrm{ij}}^{\mathrm{k}}}{\sum_{\mathrm{i}=1}^{\mathrm{m}} \mathrm{y}_{\mathrm{ij}}^{\mathrm{k}}}
$$

After calculation, each dimension indicator matrix $z^{k}$ can be obtained, $z^{k}=$ $\left(\begin{array}{ccc}\mathrm{z}_{11}^{\mathrm{k}} & \cdots & \mathrm{z}_{1 \mathrm{n}}^{\mathrm{k}} \\ \vdots & \ddots & \vdots \\ \mathrm{z}_{\mathrm{m} 1}^{\mathrm{k}} & \cdots & \mathrm{z}_{\mathrm{m} \mathrm{n}}^{\mathrm{k}}\end{array}\right), \mathrm{k}=1,2, \ldots, \mathrm{p} . \mathrm{z}_{\mathrm{m} \mathrm{n}}^{\mathrm{k}}$ represents the proportion of $\mathrm{n}_{\mathrm{k}}^{\text {th }}$ indicator of the $\mathrm{k}^{\text {th }}$ dimension of the $\mathrm{m}^{\text {th }}$ country.

The entropy value of $\mathrm{j}^{\text {th }}$ indicator for the $\mathrm{k}^{\text {th }}$ dimension is defined as

$$
e_{\mathrm{j}}^{k}=-\frac{1}{-\ln m} \sum_{i=1}^{m} z_{\mathrm{ij}}^{\mathrm{k}} \ln z_{\mathrm{i} j}^{\mathrm{k}}
$$

In particular, as $\ln z_{i n}^{k}$ has no meaning when $z_{i j}^{k}=0, z_{i j}^{k}$ is redefined as $z_{i j}^{k}=\frac{q+y_{i j}^{k}}{\sum_{i=1}^{m}\left(q+y_{i j}^{k}\right)}$. Among them, $\mathrm{q}=1.0 \times 10^{-7}$. Thus, the entropy vector $\mathrm{e}_{\mathrm{k}}=\left[\mathrm{e}_{1}^{\mathrm{k}}, \mathrm{e}_{1}^{\mathrm{k}}, \cdots, \mathrm{e}_{\mathrm{n}_{\mathrm{k}}}^{\mathrm{k}}\right]$ can be calculated. 
The weight of the $\mathrm{j}^{\text {th }}$ indicator of the $\mathrm{k}^{\text {th }}$ dimension is defined as

$$
a_{j}^{k}=\frac{1-e_{j}^{k}}{\sum_{k=1}^{p} \sum_{j=1}^{n_{k}}\left(1-e_{j}^{k}\right)}, k=1,2, \cdots, p, j=1,2, \cdots, n_{k}
$$

After calculation, the indicators weight matrix $A^{k}$ can be obtained, $A^{k}=\left[a_{1}^{k}, a_{2}^{k}, \cdots, a_{1 n_{k}}^{k}\right], k=$ $1,2, \cdots, p$. Correspondingly, the weights of the dimensions can be obtained by summing the weights of the indicators (see the Table 4 for specific calculation results).

The membership function for each risk level of membership is Equation (A7)

$$
\mathrm{r}_{\mathrm{ij}}^{\mathrm{k}} \mathrm{x}=\left\{\begin{array}{c}
1-\frac{\max \left\{\mathrm{c}_{\mathrm{j}, 1}-\mathrm{x}, \mathrm{x}-\mathrm{c}_{\mathrm{j},(1+1)}\right\}}{\max \left\{\mathrm{c}_{\mathrm{j}, 1}-\operatorname{minx}, \operatorname{maxx}-\mathrm{c}_{\mathrm{j},(1+1)}\right\}} x \notin\left[\mathrm{c}_{\mathrm{j}, 1}, \mathrm{c}_{\mathrm{j},(1+1)}\right] \\
1 \quad x \in\left[\mathrm{c}_{\mathrm{j}, 1}, \mathrm{c}_{\mathrm{j},(1+1)]}\right.
\end{array}\right.
$$

where $\mathrm{i}=1,2, \cdots, \mathrm{m} . \mathrm{j}=1,2, \cdots, \mathrm{n} . \mathrm{k}=1,2, \cdots, \mathrm{p} ; \mathrm{l}=0,1,2,3,4$.max represents the largest element, the maximum. min represents the smallest element, the smallest value.

Among them, the meaning of $\mathrm{r}_{\mathrm{ij}}^{\mathrm{k}}(\mathrm{x})$ is the membership degree of the $\mathrm{k}^{\text {th }}$ indicator of the $\mathrm{i}^{\mathrm{th}}$ country. The index fuzzy relation matrix $R_{\mathrm{i}}^{\mathrm{k}}$ can be obtained after calculation: $R_{\mathrm{i}}^{\mathrm{k}}=\left[\begin{array}{ccc}\mathrm{r}_{\mathrm{i} 1,0}^{\mathrm{k}} & \cdots & \mathrm{r}_{\mathrm{i} 1,4}^{\mathrm{k}} \\ \vdots & \ddots & \vdots \\ \mathrm{rin}_{\mathrm{k}, 0}^{\mathrm{k}} & \cdots & \mathrm{r}_{\mathrm{in}_{\mathrm{k}}, 4}^{\mathrm{k}}\end{array}\right]$, where $\mathrm{i}=1,2, \cdots, \mathrm{m} ; \mathrm{k}=1,2, \cdots, \mathrm{p}$.

After further calculation, the membership degree of each country $B_{i}^{k}$ can be obtained by

$$
B_{i}^{k}=A^{k} \times R_{i}^{k}=\left[a_{1}^{k}, a_{2}^{k}, \cdots, a_{n_{k}}^{k}\right] \times\left[\begin{array}{ccc}
r_{i 1,0}^{k} & \cdots & r_{i 1,4}^{k} \\
\vdots & \ddots & \vdots \\
r_{i_{k}, 0}^{k} & \cdots & r_{i_{k}, 4}^{k}
\end{array}\right]=\left[b_{i, 0}^{k}, b_{i, 1}^{k}, \cdots, b_{i, 4}^{k}\right]
$$

The meaning of $b_{i, n_{k}}^{k}$ is the evaluation value of the membership level of the $k^{\text {th }}$ indicator of the $i^{\text {th }}$ country to different risk levels. The matrix of overseas electric power investment risk assessment is

$$
\begin{gathered}
\mathrm{C}_{\mathrm{i}}=\left[\begin{array}{c}
\mathrm{B}_{\mathrm{i}}^{1} \\
\mathrm{~B}_{\mathrm{i}}^{2} \\
\vdots \\
\mathrm{B}_{\mathrm{i}}^{\mathrm{p}}
\end{array}\right]=\left[\begin{array}{ccc}
\mathrm{b}_{\mathrm{i}, 0}^{\mathrm{k}} & \cdots & \mathrm{b}_{\mathrm{i}, 4}^{\mathrm{k}} \\
\vdots & \ddots & \vdots \\
\mathrm{b}_{\mathrm{i}, 0}^{\mathrm{p}} & \cdots & \mathrm{b}_{\mathrm{i}, 4}^{\mathrm{p}}
\end{array}\right] \\
\mathrm{V}_{\mathbf{i}}=\mathrm{W} \times \mathrm{C}_{\mathrm{i}}=\left[\mathrm{w}^{1}, \mathrm{w}^{2}, \cdots, \mathrm{w}^{\mathrm{p}}\right] \times\left[\begin{array}{c}
\mathrm{B}_{\mathrm{i}}^{1} \\
\mathrm{~B}_{\mathrm{i}}^{2} \\
\vdots \\
\mathrm{B}_{\mathrm{i}}^{\mathrm{p}}
\end{array}\right]=\left[\mathrm{w}^{1}, \mathrm{w}^{2}, \cdots, \mathrm{w}^{\mathrm{p}}\right] \times\left[\begin{array}{ccc}
\mathrm{b}_{\mathrm{i}, 0}^{\mathrm{k}} & \cdots & \mathrm{b}_{\mathrm{i}, 4}^{\mathrm{k}} \\
\vdots & \ddots & \vdots \\
\mathrm{b}_{\mathrm{i}, 0}^{\mathrm{p}} & \cdots & \mathrm{b}_{\mathrm{i}, 4}^{\mathrm{p}}
\end{array}\right] \\
=\left[\mathrm{v}_{\mathrm{i}, 0}, \mathrm{v}_{\mathrm{i}, 1}, \cdots, \mathrm{v}_{\mathrm{i}, 4}\right]
\end{gathered}
$$

Correspondingly, the meaning of $v_{i}$ is the evaluation result of the membership degree to each risk level. According to the fuzzy evaluation theory, the final country investment risk evaluation level is the risk level corresponding to the maximum value. 
Table A1. Original data and standard data of coal power economy.

\begin{tabular}{|c|c|c|c|c|c|c|c|c|c|c|}
\hline \multirow[b]{2}{*}{ Country } & \multicolumn{5}{|l|}{ Original Data } & \multicolumn{5}{|c|}{ Standardized Data } \\
\hline & $\begin{array}{l}\text { Coal Surplus } \\
\text { Degree }\end{array}$ & $\begin{array}{l}\text { Proportion of } \\
\text { Electric Coal }\end{array}$ & $\begin{array}{l}\text { Coal Power } \\
\text { Planning }\end{array}$ & $\begin{array}{l}\text { Proportion of Coal } \\
\text { and Electricity }\end{array}$ & $\begin{array}{l}\text { Coal Power } \\
\text { Growth }\end{array}$ & $\begin{array}{l}\text { Coal Surplus } \\
\text { Degree }\end{array}$ & $\begin{array}{l}\text { Proportion of } \\
\text { Electric Coal }\end{array}$ & $\begin{array}{l}\text { Coal Power } \\
\text { Planning }\end{array}$ & $\begin{array}{l}\text { Proportion of } \\
\text { Coal and Electricity }\end{array}$ & $\begin{array}{l}\text { Coal Power } \\
\text { Growth }\end{array}$ \\
\hline Pakistan & 735.73 & $1.85 \%$ & 12,385 & 0.16 & $33.64 \%$ & 0.6905 & 0.0000 & 0.4551 & 1.0000 & 0.3074 \\
\hline Poland & 178.57 & $67.76 \%$ & 9090 & 82.99 & $-0.37 \%$ & 0.4307 & 0.6871 & 0.4106 & 0.1078 & 0.1016 \\
\hline Korea & 184.67 & $69.72 \%$ & 7359 & 42.41 & $1.67 \%$ & 0.4356 & 0.7075 & 0.3826 & 0.5449 & 0.1139 \\
\hline Russia & 431.46 & $46.52 \%$ & 720 & 14.90 & $-0.88 \%$ & 0.5779 & 0.4656 & 0.1763 & 0.8412 & 0.0985 \\
\hline Philippines & 44.52 & $79.04 \%$ & 12,141 & 42.78 & $9.85 \%$ & 0.2711 & 0.8046 & 0.4521 & 0.5409 & 0.1634 \\
\hline Kazakhstan & 238.85 & $54.71 \%$ & 636 & 71.95 & $2.89 \%$ & 0.4746 & 0.5510 & 0.1692 & 0.2268 & 0.1213 \\
\hline Cambodia & 0.00 & $97.79 \%$ & 3325 & 28.21 & $148.06 \%$ & 0.0000 & 1.0000 & 0.2936 & 0.6978 & 1.0000 \\
\hline Czech & 79.19 & $72.74 \%$ & 660 & 51.46 & $-3.48 \%$ & 0.3284 & 0.7389 & 0.1713 & 0.4475 & 0.0827 \\
\hline Malaysia & 70.16 & $89.21 \%$ & 2600 & 37.86 & $7.30 \%$ & 0.3155 & 0.9106 & 0.2705 & 0.5940 & 0.1480 \\
\hline Bangladesh & 314.81 & $11.50 \%$ & 21,998 & 1.97 & $9.80 \%$ & 0.5203 & 0.1006 & 0.5512 & 0.9805 & 0.1631 \\
\hline Burma & 9.44 & $15.73 \%$ & 2030 & 2.02 & $-17.15 \%$ & 0.1617 & 0.1447 & 0.2491 & 0.9799 & 0.0000 \\
\hline South Africa & 137.75 & $64.00 \%$ & 11,892 & 93.00 & $-0.72 \%$ & 0.3950 & 0.6479 & 0.4490 & 0.0000 & 0.0994 \\
\hline Thailand & 167.83 & $51.87 \%$ & 5256 & 21.64 & $6.92 \%$ & 0.4219 & 0.5215 & 0.3420 & 0.7686 & 0.1457 \\
\hline Turkey & 256.33 & $53.91 \%$ & 42,890 & 30.27 & $9.71 \%$ & 0.4859 & 0.5426 & 0.6886 & 0.6757 & 0.1625 \\
\hline Ukraine & 1130.36 & $59.44 \%$ & 1320 & 38.74 & $0.27 \%$ & 0.7967 & 0.6003 & 0.2158 & 0.5845 & 0.1054 \\
\hline Singapore & 0.00 & $62.90 \%$ & 0 & 1.10 & $25.29 \%$ & 0.0000 & 0.6364 & 0.0000 & 0.9899 & 0.2569 \\
\hline New Zealand & 2235.01 & $32.97 \%$ & 0 & 4.50 & $4.62 \%$ & 1.0000 & 0.3244 & 0.0000 & 0.9532 & 0.1317 \\
\hline Israel & 0.00 & $96.80 \%$ & 0 & 49.56 & $-2.91 \%$ & 0.0000 & 0.9897 & 0.0000 & 0.4680 & 0.0862 \\
\hline India & 162.28 & $67.03 \%$ & 131,359 & 75.08 & $10.19 \%$ & 0.4172 & 0.6795 & 1.0000 & 0.1931 & 0.1655 \\
\hline Indonesia & 65.24 & $76.60 \%$ & 37,905 & 52.65 & $15.41 \%$ & 0.3079 & 0.7792 & 0.6608 & 0.4346 & 0.1970 \\
\hline Vietnam & 90.34 & $52.90 \%$ & 46,525 & 24.53 & $14.60 \%$ & 0.3432 & 0.5321 & 0.7075 & 0.7375 & 0.1922 \\
\hline
\end{tabular}


The calculations for other dimensions are similar. Due to space limitations, it is not shown here in detail.

Table A2. Membership results of the integrated evaluation of four-dimensional indicator system.

\begin{tabular}{ccccccc}
\hline Country & Highest Risk & Higher Risk & Medium Risk & Lower Risk & Lowest Risk & Risk Level \\
\hline Poland & 0.5334 & 0.6465 & 0.7917 & 0.9111 & 0.2835 & lower risk \\
Korea & 0.4876 & 0.6055 & 0.7297 & 0.8750 & 0.2800 & lower risk \\
New Zealand & 0.3473 & 0.4099 & 0.4925 & 0.6078 & 0.2855 & lower risk \\
Malaysia & 0.6033 & 0.7022 & 0.8205 & 0.8755 & 0.2582 & lower risk \\
Czech & 0.4697 & 0.6016 & 0.7802 & 0.9444 & 0.3027 & lower risk \\
Singapore & 0.2178 & 0.2263 & 0.2501 & 0.4178 & 0.2939 & lower risk \\
Israel & 0.5487 & 0.6066 & 0.6551 & 0.7862 & 0.2730 & lower risk \\
Philippines & 0.6994 & 0.8454 & 0.8876 & 0.8046 & 0.2162 & medium risk \\
Russia & 0.7309 & 0.7918 & 0.8024 & 0.7225 & 0.1945 & medium risk \\
Kazakhstan & 0.6868 & 0.7554 & 0.7913 & 0.7102 & 0.2032 & medium risk \\
Thailand & 0.6967 & 0.8419 & 0.9167 & 0.8027 & 0.1994 & medium risk \\
Turkey & 0.6907 & 0.8087 & 0.8934 & 0.8622 & 0.2215 & medium risk \\
Indonesia & 0.7296 & 0.8747 & 0.8992 & 0.7536 & 0.1916 & medium risk \\
South Africa & 0.7215 & 0.7695 & 0.8326 & 0.7586 & 0.1927 & medium risk \\
India & 0.8036 & 0.8745 & 0.7704 & 0.6806 & 0.1755 & higher risk \\
Vietnam & 0.7121 & 0.7976 & 0.7511 & 0.7208 & 0.2090 & higher risk \\
Ukraine & 0.8433 & 0.8561 & 0.7755 & 0.6221 & 0.1464 & higher risk \\
Cambodia & 0.7352 & 0.6834 & 0.5599 & 0.5007 & 0.1559 & highest risk \\
Burma & 0.8182 & 0.7406 & 0.5793 & 0.4972 & 0.1433 & highest risk \\
Pakistan & 0.8806 & 0.8189 & 0.6350 & 0.5016 & 0.1247 & highest risk \\
Bangladesh & 0.8539 & 0.8324 & 0.6513 & 0.5347 & 0.1349 & highest risk \\
\hline
\end{tabular}

Table A3. Membership results of the integrated evaluation of nine-dimensional indicator system.

\begin{tabular}{ccccccc}
\hline Country & Highest Risk & Higher Risk & Medium Risk & Lower Risk & Lowest Risk & Risk Level \\
\hline Cambodia & 0.4676 & 0.4409 & 0.4091 & 0.3954 & 0.6619 & lowest risk \\
Burma & 0.5685 & 0.5101 & 0.4446 & 0.4455 & 0.6102 & lowest risk \\
Philippines & 0.7033 & 0.7783 & 0.8225 & 0.8303 & 0.6865 & lower risk \\
Vietnam & 0.6662 & 0.7467 & 0.7757 & 0.8232 & 0.6671 & lower risk \\
Korea & 0.7249 & 0.7798 & 0.8154 & 0.8212 & 0.5894 & lower risk \\
Poland & 0.7082 & 0.7757 & 0.7953 & 0.8186 & 0.5805 & lower risk \\
India & 0.6946 & 0.7345 & 0.7288 & 0.7627 & 0.7103 & lower risk \\
New Zealand & 0.6243 & 0.6575 & 0.6665 & 0.6759 & 0.5762 & lower risk \\
Thailand & 0.7220 & 0.8602 & 0.9427 & 0.8804 & 0.5830 & medium risk \\
Malaysia & 0.7098 & 0.8285 & 0.8829 & 0.8664 & 0.6285 & medium risk \\
Indonesia & 0.7443 & 0.8633 & 0.8691 & 0.8071 & 0.5874 & medium risk \\
Turkey & 0.7522 & 0.8441 & 0.8620 & 0.8255 & 0.5621 & medium risk \\
Kazakhstan & 0.7287 & 0.7845 & 0.7765 & 0.7350 & 0.5609 & medium risk \\
Russia & 0.7164 & 0.7733 & 0.7833 & 0.7664 & 0.5599 & medium risk \\
Ukraine & 0.8418 & 0.8915 & 0.8132 & 0.6885 & 0.4137 & higher risk \\
South Africa & 0.7376 & 0.7953 & 0.8027 & 0.7826 & 0.6521 & higher risk \\
Czech & 0.7333 & 0.7877 & 0.7848 & 0.7805 & 0.5369 & higher risk \\
Bangladesh & 0.7198 & 0.7512 & 0.7055 & 0.6947 & 0.6349 & higher risk \\
Pakistan & 0.7307 & 0.7354 & 0.7196 & 0.7224 & 0.5421 & higher risk \\
Singapore & 0.6351 & 0.6493 & 0.5998 & 0.6059 & 0.5720 & higher risk \\
Israel & 0.7953 & 0.7778 & 0.6987 & 0.6562 & 0.4446 & highest risk \\
\hline
\end{tabular}

\section{References}

1. Ming, Z. The power cooperation between China and Southeast Asia under the "One Belt, One Road" strategy. China Power Enterp. Manag. 2015, 23, 75-77.

2. Tianrong, W. Lighting up the "Belt and Road"-A new chapter in the development of "going out" for Chinese power companies. China Power Enterp. Manag. 2015, 13, $26-28$.

3. Yi, W. Chinese power companies carry out investment business in 52 countries along the "Belt and Road". Chin. Electr. Power 2017, 08-22. 
4. World Energy Outlook 2017. Available online: https://webstore.iea.org/world-energy-outlook-2017 (accessed on 20 August 2018).

5. Grinmsy, D.; Lewis, M.K. Evaluating the risks of public private partnerships for infrastructure projects. Int. J. Proj. Manag. 2002, 20, 227-231.

6. Coase, R.H. The problem of social cost. Int. J. Proj. Manag. 2002, 20, 227-231.

7. Shakouri, G.H.; Eghlimi, M.; Manzoor, D. Economically optimized electricity trade modeling: Iran-Turkey case. Energy Policy 2009, 37, 472-483. [CrossRef]

8. Liu, Y.A.; Xiao, G. Purchase allocation and demand bidding in electric Power markets. IEEE Trans. Power Syst. 2003, 18, 106-112.

9. Dockner, E.J.; Kucsera, D.; Rammerstorfer, M. Investment, firm value, and risk for a system operator balancing energy grids. Energy Econ. 2013, 37, 182-192. [CrossRef]

10. Farfan, J.; Breyer, C. Structural changes of global power generation capacity towards sustainability and the risk of stranded investments supported by a sustainability indicator. J. Clean. Prod. 2017, 141, 370-384. [CrossRef]

11. Gal, N.; Milstein, I.; Tishler, A.; Woo, C.K. Fuel cost uncertainty, capacity investment and price in a competitive electricity market. Energy Econ. 2017, 61, 233-240. [CrossRef]

12. Tietjen, O.; Pahle, M.; Fuss, S. Investment risks in power generation: A comparison of fossil fuel and renewable energy dominated markets. Energy Econ. 2016, 58, 174-185. [CrossRef]

13. Liwei, Z. Structure Analysis of Power Investment Risk Elements and the Grade Synthesis Appraises of Risk. Master's Thesis, Harbin Institute of Technology, Harbin, China, July 2007.

14. Min, L.; Lixia, W. Risk management framework for power generation companies in power market environment. Power Syst. Autom. 2004, 28, 1-6.

15. Chongqing, K.; Lichao, B. Risk decisions of power producers in the power market. Proc. CSEE 2004, 24, 1-6.

16. Zhang, M.M.; Zhou, P.; Zhou, D.Q. A real options model for renewable energy investment with application to solar photovoltaic power generation in China. Energy Econ. 2016, 59, 213-226. [CrossRef]

17. Duan, F.; Ji, Q.; Liu, B.Y.; Fan, Y. Energy investment risk assessment for nations along China's Belt \& Road Initiative. J. Clean. Prod. 2018, 170, 538-547.

18. Yuan, J.; Wu, M.; Zhang, W.; Guo, Y.; Xiong, M. Coal Power Environmental Stress Testing in China. Sustainability 2018, 10, 2151. [CrossRef]

19. Yuan, J.H.; Lei, Q.; Xiong, M.P.; Guo, J.S. The prospective of coal power in China: Will it reach a plateau in the coming decade? Energy Policy 2016, 98, 495-504. [CrossRef]

20. Yuan, J.H.; Ding, W.; Hu, Z.G. Analysis of cointegration and fluctuations of power consumption and China's economic development. Grid Technol. 2006, 9, 10-15.

21. Yuan, J.H.; Li, P.; Wang, Y.; Liu, Q. Coal power overcapacity and investment bubble in China during 2015-2020. Energy Policy 2016, 97, 136-144. [CrossRef]

22. Hao, C.; Guo, Y.; Yuan, J.; Wu, M.; Li, D.; Zhou, Y.; Kang, J. ESG and Corporate Financial Performance: Empirical Evidence from China's Listed Power Generation Companies. Sustainability 2018, 10, 2607. [CrossRef]

23. Yuan, J.; Xu, Y.; Hu, Z.; Zhao, C.; Xiong, M.; Guo, J. Peak energy consumption and $\mathrm{CO}_{2}$ emissions in China. Energy Policy 2014, 68, 508-523. [CrossRef]

24. Na, C.N.; Yuan, J.H.; Xu, Y.; Hu, Z. Penetration of clean coal technology and its impact on China's power industry. Energy Strategy Rev. 2015, 7, 1-8. [CrossRef]

25. Yuan, J.; Zhao, C.; Yu, S.; Hu, Z. Electricity consumption and economic growth in China: Cointegration and co-feature analysis. Energy Econ. 2007, 29, 1179-1191. [CrossRef]

26. Lou, C.W. A Sovereign Credit Risk Assessment Study on the Basis of the Integrated Method of Multi-Objective Decision Making and Data Mining. Ph.D. Thesis, University of Electronic Science and Technology of China, Chengdu, China, April 2012.

27. Herring, R. Managing International Risk; Cambridge University Press: Cambridge, UK, 1983; pp. 56-97.

28. Cosset, J.C.; Suret, J.M. Political risk and the benefit of international portfolio diversification. J. Int. Bus. Stud. 1995, 26, 301-318. [CrossRef]

29. Wang, C. Comparative study on national risk assessment index system. Econ. Manag. Res. 2008, 6, 51-55.

30. World Development Indicator. Available online: https://datacatalog.worldbank.org/dataset/worlddevelopment-indicators (accessed on 20 August 2018). 
31. Index of Economic Freedom. Available online: https://www.heritage.org/index/about (accessed on 20 August 2018).

32. Numbeo. Available online: https:/ / www.numbeo.com/common/ (accessed on 20 August 2018).

33. Wordwide Governance Indicators. Available online: http://info.worldbank.org/governance/wgi/index. aspx\#home (accessed on 20 August 2018).

34. World Bank Open Data. Available online: https://data.worldbank.org (accessed on 20 August 2018).

35. National Bureau of Statistics of China. Available online: http://www.stats.gov.cn/english/ (accessed on 20 August 2018).

36. National Information Center "Belt and Road" Big Data Center. "Belt and Road" Big Data Report; The Commercial Press: Beijing, China, 2016; pp. 1-27.

37. Chinese Foreign Ministry. Available online: http://www.fmprc.gov.cn/web/ (accessed on 20 August 2018).

38. International Energy Agency. Available online: https://www.iea.org (accessed on 20 August 2018).

39. Aqueduct Projected Water Stress Country Rankings. Available online: http://www.wri.org/publication/ aqueduct-projected-water-stress-country-rankings (accessed on 20 August 2018).

40. World Health Organization. Available online: http:/ / www.who.int (accessed on 20 August 2018).

41. Intended Nationally Determined Contributions-Post2020 Climate Action Commitments. Available online: http:/ / www.wri.org/our-work/topics/indcs (accessed on 20 August 2018).

42. U.S. Energy Information Administration. Available online: https:/ /www.eia.gov (accessed on 20 August 2018).

43. Global Coal Plant Tracker. Available online: https://endcoal.org/global-coal-plant-tracker/ (accessed on 20 August 2018).

44. Bp. Available online: https:/ / www.bp.com (accessed on 20 August 2018).

45. Report on Development of China's Outward Investment and Economic Cooperation. Available online: http:/ / fec.mofcom.gov.cn/article/tzhzcj/tzhz/upload/zgdwtzhzfzbg2017.pdf (accessed on 20 August 2018).

46. Word Bank Group. Power Shortage Status Report 2017. Available online: https://openknowledge. worldbank.org/handle/10986/26646 (accessed on 20 August 2018).

47. Electrical Planning and Design Institute. China Electric Power Development Report 2016. Available online: http:/ / www.cec.org.cn/guihuayutongji/gongzuodongtai/2017-09-11/172982.html (accessed on 20 August 2018).

48. Sustainable Development Goals. Available online: https://www.un.org/sustainabledevelopment/ (accessed on 20 August 2018).

49. Mo, L.S. Solution to Green Investment Cost and Benefit on One Belt and One Road; People's Press: Beijing, China, 2018; pp. 9-21.

50. Xu, S.S. One Belt and One Road Two-way Investment Research and Case Analysis; Machine Press: Beijing, China, 2016; pp. 9-12. 